\title{
A survey-based analysis of life-long learning patterns of young entrepreneurs
}

\author{
Johana RîNCIOG \\ The Bucharest University of Economic Studies, Bucharest, Romania \\ johana.rinciog@gmail.com
}

\begin{abstract}
Our approach, in this paper, is focused on life-long learning tools that are available for young Romanian entrepreneurs, in their early career stages. Life-long learning in the case of entrepreneurs is not a topic widely covered in scientific literature up to this moment. Most of the scientific papers related to entrepreneurship focus on the idea of innovation and creativity that characterizes entrepreneurship. On the other side, the scientific literature that considers life-long learning, discusses the case of employees or managers, who are required to improve their knowledge and skills in order to perform at the work place. For the current paper, it was aimed to survey the lifelong learning tools available to young Romanian people and to evaluate their efficiency with the help of interviews with young entrepreneurs on their educational path. Otherwise stated, we intended to provide more insights on the learning methods and practices of entrepreneurs, and to establish whether the current formal education represents a strong basis for entrepreneurs' life-long learning. The research that we performed revealed that young Romanian entrepreneurs practice indeed a lifelong learning based not as much on formal education, as on learning by practicing and networking. Starting from the observations obtained, it was conceived, based on current European best practices and projective discussions with the same young entrepreneurs, a set of life-long learning initiatives that may be promoted in the entrepreneurial community, and we identify the actual steps to be taken by life-long learning education providers in order to implement these initiatives. This paper's conclusions serve as both a state of the art analysis, in a field which is vital for entrepreneurs surviving in competitive environments, and as a prospective guide for improving the present market of life-long learning programs.
\end{abstract}

Keywords: entrepreneurship, life-long learning, emotional intelligence.

\section{Introduction}

Lifelong learning otherwise known as ongoing learning, characterizes humanity since its beginnings, but the term's understanding changed with the trends that occurred for each generation. For example, lifelong learning in $20^{\text {th }}$ century is perceived as consisting of efforts for developing skills and building competencies that will help individuals to succeed in their careers. This new significance of lifelong learning was sustained by globalization and technological innovations (Jirgensons, 2015). Nowadays, the development of communication technologies allows individuals to obtain knowledge and expertise only with the click of a mouse, and this means that in a short time, certain skills and businesses become obsolete and irrelevant.

Entrepreneurs are not an exception from this rule. Entrepreneurial success is achieved through continuous effort and improvement, even after the entrepreneur launches the business and starts to gain profit. In other words, the entrepreneurial path should not be characterized by a complacent attitude, but by a permanent willingness to gather more knowledge and to gain new skills that will help entrepreneurs to face the competition. In support of these affirmation, Laal (2013) sustains that the commitment for lifelong learning 
is one of the criteria that differentiates successful entrepreneurs from those with medium achievements.

The opportunities available nowadays, are seen also in the existent learning materials and activities, which entrepreneurs could use in order to improve their knowledge and skills. As Kakouris (2015) sustains, learning new skills does not necessarily mean to obtain a certificate. Other learning activities such as reading an article or reflecting over past business mistakes will help entrepreneurs to achieve personal development.

\section{Literature review}

\section{Lifelong learning}

Lifelong learning is a concept used in order to describe the learning efforts of individuals, which are performed during their entire life or throughout adult life (Aleandri and Refrigeri, 2013). As is can be seen from the author's perspective over the concept, lifelong learning is practiced outside the traditional schooling, it may cover a wide range of topics, and it may occur at different times or in different places. Areekul et al (2015) support the idea that lifelong learning is a characteristic of organizations or communities that take advantage of opportunities to improve their knowledge by learning from specialists, using information technology, local wisdom, and so on.

The concept of lifelong learning was widely approached by researchers because important benefits are obtained from practicing it, such as the following: increased creativity, identification of solutions, increased willingness to stay updated with the industry changes, improved ideas for delivering more valuable services, achieving sustainable business success in a changing business context, and others (Kakouris, 2015).

Jirgenson (2015) offers a series of examples of lifelong learning practices, which he considers as opportunities for entrepreneurs to enrich their business knowledge or to improve their skills. Firstly, the author makes reference to MBA courses, Phds, and online courses. Entrepreneurs choose the type of formal learning depending on the skills they intend to improve. A second proposal is networking. Networking is a learning practice that involves exchanging experience with other entrepreneurs. Also, entrepreneurs could exchange ideas on future activities they plan to do, and which were already performed by others. Thirdly, reflection on past experiences is a practice that would enable entrepreneurs to understand mistakes occurred in the past and to make sustainable plans for the future. Fourthly, the author recalls about advice from mentors, business partners, family, etc.

Areekul et al (2015) emphasizes that entrepreneurs who put effort in practicing one or several of the above mentioned learning activities are mostly interested in getting updated with the newest information on different topics of interest for them. As it was mentioned previously, trends in business and customers preferences change at a fast pace, reason for which these entrepreneurs are required to constantly gather knowledge on certain topics, such as international economic trends, technology, consumer behavior, industry trends, marketing trends.

To sum up, lifelong learning is a practice that characterizes humanity from its beginnings until modern times because it lays at the basis of people's need for development (Hanewald, 2012). Lifelong learning consists of various activities and tools through which individuals, and in particular, entrepreneurs, have the possibility to gather more knowledge, and to improve or develop more skills. Given the rate of change that 
characterizes these modern times, lifelong learning appears as a necessity for entrepreneurs who want to keep up with these changes, to build sustainable businesses and to grow these businesses.

\section{Emotional intelligence as a facilitator of lifelong learning}

After understanding the importance of lifelong learning, this section of the paper will explain the role of emotional intelligence for enhancing ongoing education. The reason why this perspective was chosen is because lifelong learning requires entrepreneurs to be selfstarters. In other words, ongoing education is a practice of highly motivated individuals. People who achieve growth in their personal lives, are able to be successful professionally and to build a strong business (Aleandri and Refrigeri, 2013).

Nowadays, the modern technology facilitates people's access to knowledge, but it depends on each individual's ability to find motivation and to take advantage of this opportunity. The first step to be performed in this sense, is to have an open mind (Laal, 2013). In order to embrace the new knowledge, one has to remove assumptions or convictions, to step outside the comfort zone, and to reflect over the information that challenges his/her worldview. By digging deeper into the wealth of new information and knowledge, one is able to expand his/her mind and vision (Bratianu, 2007, 2009).

Today, many people complain about not finding the proper time in the schedule for learning. However, self-starters manage their time in a way that allows them to invest in their development. Through a continuous striving for knowledge, these people manage to achieve success not only in their businesses, but also in other spheres of their lives (Laal, 2013). These people train their mind in order to find ways and time for daily learning. Some examples in this sense could be: listening to audio-books, seeking help from a mentor, attending personal enrichment classes, reading a book while waiting in line, replacing the time spent on social media with learning activities, interacting with other professionals in the field, asking questions, and so on (Aleandri and Refrigeri, 2013).

As affirmed by (Hanewald, 2012), a continuous effort towards improving knowledge helps entrepreneurs not only to accomplish their objectives, but also to increase their desire for more knowledge.

\section{Research design Methodology}

The research methods selected for this paper are the interview, as a mean to perform qualitative research and the survey, for performing quantitative research. The interview was selected because it allows the researcher to understand the story or the experiences of interviewees. Due to the fact that an interview is a face-to-face discussion, the interviewer has an opportunity to formulate questions adapted to each case, and thus to obtain in depth information (Hollowitz and Wilson, 1993). There are a series of advantages and disadvantages involved with using the interview as a research method.

For example, as an advantage we can emphasize the fact that interviews are a more personal form of research, in comparison with questionnaires, which allows the interviewer to ask additional questions based on the information provided by interviewee. Another advantage relates to the fact that the interviewer is able to reformulate the questions if respondents find these unclear. On the other side, interviews are time consuming not only 
when it comes to having the discussions with interviewees, but also before the actual interviews, during the preparation stage. The researcher should own or improve several skills before starting to take interviews. For example, the interviewer should have a good ability to listen and to be non-judgmental, or to be able to remember most of the ideas expressed by interviewees (Rosenthal, 2016).

For this paper, it was used a standardized open-ended interview, consisting of several open-ended questions that were addressed to all interviewees. In this way, it was easier to analyze the answers gathered from interviewees. There were performed six interviews, and the interviewees were young Romanian entrepreneurs. The following table presents some data about the profile of interviewees.

Table 1: Profile of interviewees

\begin{tabular}{|l|l|}
\hline Business name & Name of the entrepreneur \\
\hline $\begin{array}{l}\text { Anaide } \\
\text { - dress designing }\end{array}$ & Diana Mirea \\
\hline $\begin{array}{l}\text { Square Beauty Concept } \\
\text { - hairdressing, make-up } \\
\text { - coffee shop }\end{array}$ & Algayyim Zaid \\
\hline $\begin{array}{l}\text { Interactive Digital Labs } \\
\text { - online marketing }\end{array}$ & Alexandru Dudulea \\
\hline Petrolhead - online magazine for cars & Bogdan Ivan \\
\hline
\end{tabular}

Source: Author's own research.

Regarding the second method of research, the questionnaire was used in order to obtain quantitative data. There are a series of benefits derived from using a questionnaire. For instance, the questionnaire enabled collecting a large amount of data, which was analyzed with the help of a software. The information obtained from data analysis was used to test hypotheses or to identify new theories. On the other side, the limitations of the questionnaire may refer to respondents' willingness to reflect very well over the questions. Also, it is very possible that the questions do not cover all the aspects of interest for respondents, and maybe they would have added more perspectives over the topic.

For this study there were applied 30 questionnaires to young Romanian entrepreneurs, under 35 years old, who started small ventures in different sectors of activity. Out of these questionnaires, 24 were valid. The questionnaires were handed on to respondents either through e-mail, or in physical form, and the data collected was processed in Excel. Being aware about the strengths and limitations of both research methods, it was decided to use a combination of data from these two instruments.

\section{Results}

This section aims to present the results of interviews and questionnaires.

Firstly, there will be formulated a series of observations regarding the interviews. When interviewees were asked about their efforts in terms of lifelong learning, many of them emphasized the fact that a great part of their business knowledge is derived from implementing improvements in their businesses. For instance, they are opened to use the 
newest promotional techniques for their businesses, such as social media. Also, by trying different solutions for promoting their businesses, they are able to compare the benefits (time, budget, size of audience targeted) and to take decisions that are advantageous for them. Hence, we may say that entrepreneurs are hands-on persons, and most of their business knowledge is obtained from the experience gained with making business improvements.

PICBE | 316

The information gathered from interviews revealed also the fact that entrepreneurs find activities like reading business books, attending conferences, and so on, as time consuming, reason for which they are not so much interested in these. Given the fact that they have to pay attention to different aspects of their businesses, there is few time left for ongoing learning. Of course, this hypothesis should not be generalized, because the interviewees were entrepreneurs who just started their businesses. However, some of the learning practices preferred by them were reading business books, articles from online magazines, learning from other successful business men, or looking for advice from family, friends or business partners. Also, networking seems to play an important role in their development. The interviewees affirmed that they associate with groups dedicated to encouraging entrepreneurship, from several reasons: to exchange experience and knowledge with other entrepreneurs, to identify potential business partners, to promote their products or services, and so on.

To sum up the few observations withdrawn from interviews, there will be presented some connections between lifelong learning and emotional intelligence, based on the information obtained up to this moment. Even though the interviewees affirmed that they do not allocate much time to ongoing learning, there are several aspects indicating their high level of emotional intelligence. Firstly, these entrepreneurs are opened to opportunities for developing their businesses. This openness is fueled by their desire to achieve a certain vision, or to reach the business goals regardless of difficulties encountered. Having set in their minds these goals, entrepreneurs are willing to try new ideas. Affiliation is another aspect of emotional intelligence observed at interviewees. These entrepreneurs improve their business knowledge through creating more or stronger contacts with other entrepreneurs, business partners or specialists who could help them in developing the businesses.

The second stage of this paper section consists of formulating several observations based on answers received from questionnaires. The survey was focused on respondents' opinion about different practices of ongoing learning and on the difficulty to allocate sufficient time for ongoing learning.

Firstly, the respondents were required to express their opinion about the activities practiced by them as a way of life-long learning. The following graphical illustration shows the results. 


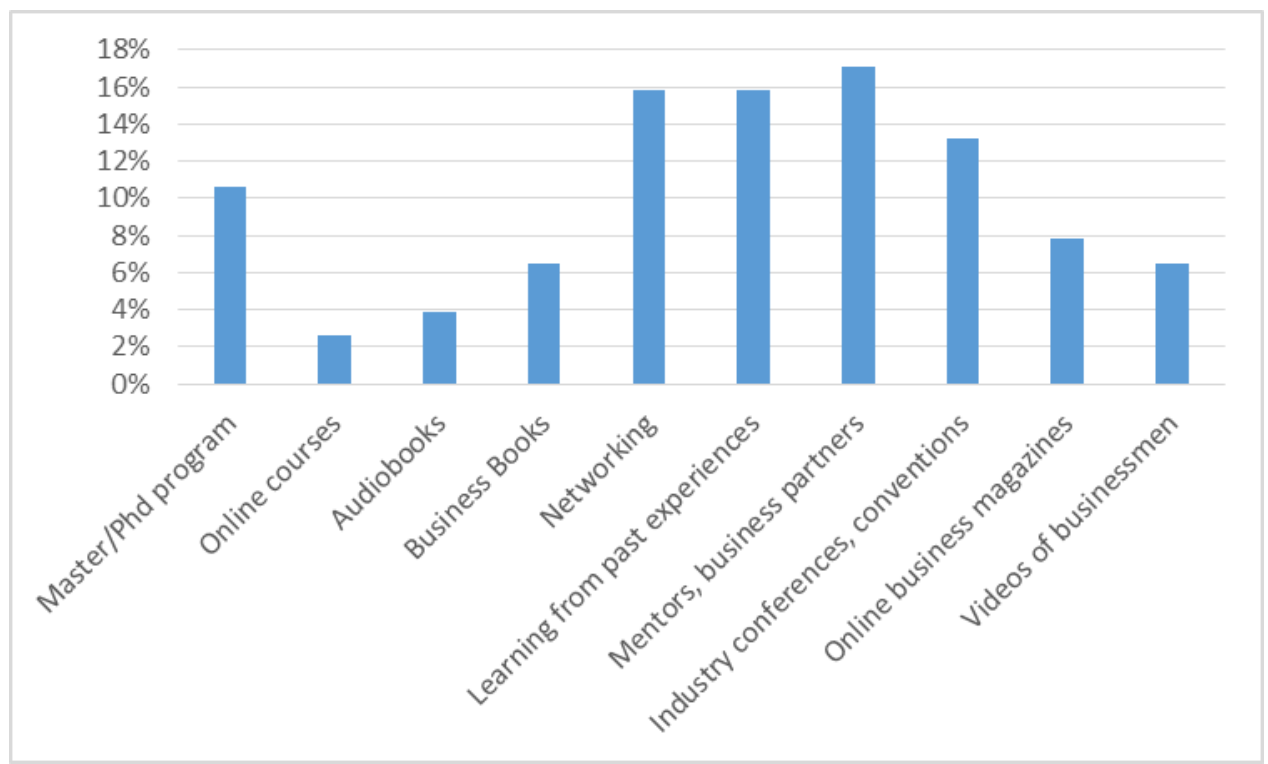

PICBE | 317

Figure 1. Practices for improving business knowledge

Source: Author's own research.

It was discovered that in the top of entrepreneurs' preferences are networking, learning from past experiences and mistakes or looking for advice from mentors, business partners or family. Other options helping entrepreneurs in their lifelong learning are the following: participation to industry conferences, trainings or conventions, following a master/phd program, reading articles from online business magazines, and watching videos of successful businessmen. As it can be seen, these findings reinforce the observations derived from interviews. Young entrepreneurs from Romania improve their business knowledge or develop their skills through experiencing different improvements or solutions for their businesses, and through sharing knowledge with other entrepreneurs or specialists in the field. Giving the fact that little attention is paid by entrepreneurs to learning materials, it results that the Romanian entrepreneurship culture has gaps in this sense, and entrepreneurs should be encouraged to educate themselves from books, articles, blogs, videos of businessmen, and so on.

Secondly, the survey was aimed at identifying possible reasons that determine entrepreneurs to invest permanently in their business knowledge. The following chart presents the weights obtained for each of the alternatives presented to respondents. It was observed that the reasons why entrepreneurs learn from past experiences and through networking, explain their choices in terms of lifelong learning practices. Most of respondents stated that they invest in their business knowledge mostly for increasing the quality of services offered to clients. In this way, they prefer to test new ideas of doing business and to see the feedback from clients, instead of reading books or articles that may provide solutions which are not any more fitted for clients' needs in these days. 


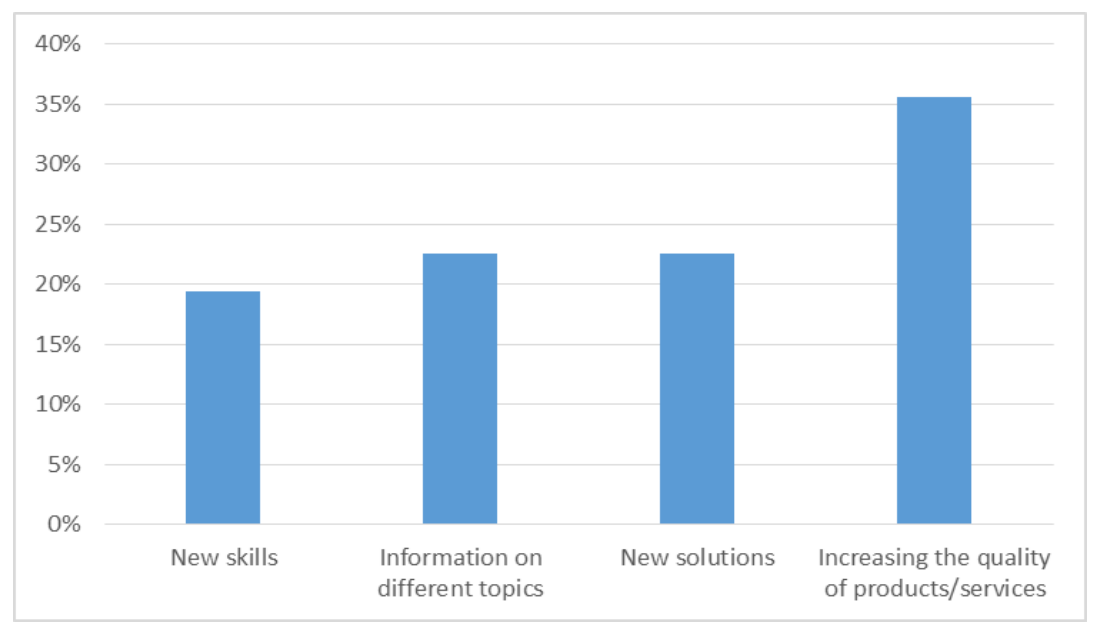

PICBE | 318

Figure 2. Reasons for improving the business knowledge

Source: Author's own research.

Nevertheless, even though changes occur very fast in today's business environment, entrepreneurs should be aware about the principles of doing business in order to understand the new ideas, and to build sustainable businesses. For example, if an entrepreneur intends to use a new promotional technique, he/she should know how to convince employees to accept this change in doing business. Without a basic knowledge of doing business and balancing all the aspects of a venture, entrepreneurs will find it more difficult to apply new ideas.

Another observation resulted from survey relates to the type of skills that entrepreneurs intend to develop through lifelong learning.

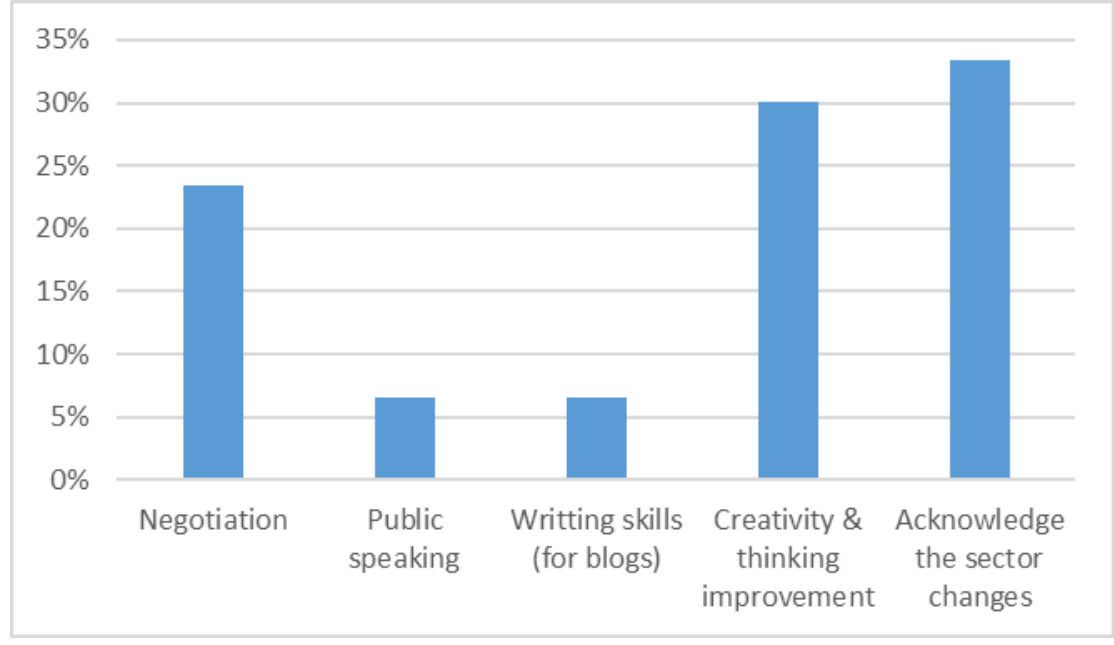

Figure 3. Skills to be developed through ongoing learning

Source: Author's own research.

The answers obtained highlight the fact that young Romanian entrepreneurs are mostly interested in increasing their interest for acknowledging the changes specific to the sector, developing their creativity and thinking, and improving negotiation skills. The fact that much attention is placed on identifying the novelties of a business sector, sustains once again the previous findings. 
The last aspect emphasized in the survey referred to entrepreneurs' willingness to allocate time for ongoing learning and the results are presented below.

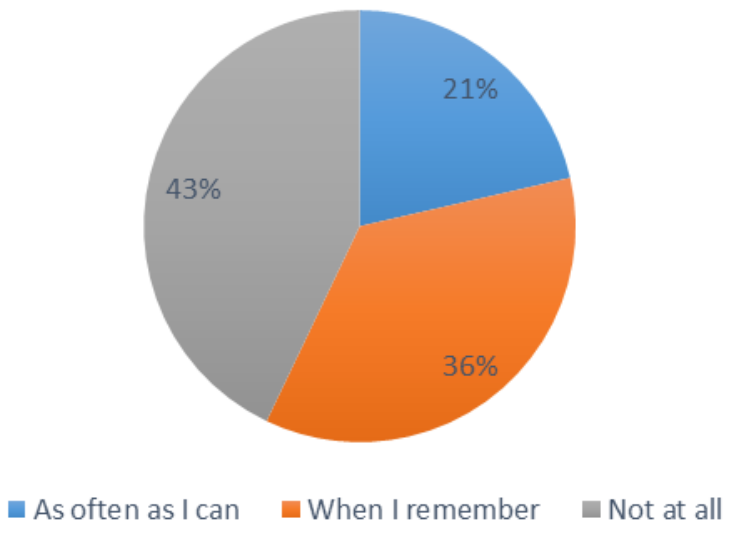

PICBE | 319

\section{Figure 4: Willingness to allocate time for ongoing learning}

Source: Author's own research.

It was observed that entrepreneurs hardly find enough time to allocate for ongoing learning. Moreover, they lack the motivation to find time for learning. Less than a third of respondents sustained that they listen audiobooks in traffic, read books while waiting in line or replace the time spent on social media with reading business news.

\section{Discussion}

The research instruments used for this paper revealed that entrepreneurs practice openness towards adopting new technologies, thus they are interested in improving their knowledge about trends in technology, marketing, customer approach and so on. Often, they gather knowledge and experience in this sense through practice or through an exchange of knowledge with more experienced entrepreneurs, and to a lower degree through reading. Even though entrepreneurs' willingness to get updated is worth to be appraised, their decisions and activities should not be performed without a strategy. Trying a certain technology or promotional tool will offer entrepreneurs a glimpse of the benefits gained. However, without a strategy, trying will not get them to where they wish to.

Another observation derived from this research reveals that young Romanian entrepreneurs prefer to focus their learning efforts on exchanging knowledge with specialists or other entrepreneurs, rather than using learning materials (books, articles, blogs, videos of businessmen, and so on.) Even though practice provides them with a great deal of knowledge, learning materials offer the opportunity to expand the horizons, to take into consideration practices from other regions of the world, to identify successful principles, and so on. However, the problem reported in this study is not the accessibility to these materials, but the willingness of entrepreneurs to manage their time in such a way that they would be able to read or listen learning materials.

Even though time management is a skill that can be developed or improved at any age, perhaps the best time for doing it is during the years of study, when pupils or students are open to learn skills and to improve their knowledge. During the study years, students should be accustomed with the idea of learning outside the classes, having initiative in choosing additional learning activities, and finding time to invest in knowledge. Enhancing 
these aspects of student life should be based on a deeper understanding of emotional intelligence, and on the available tools and practices for achieving the previously mentioned vision of education.

\section{Conclusion}

The topic of lifelong learning for entrepreneurs was selected starting from the assumption that the business environment changes at a fast pace, and entrepreneurs are required to find ways to adapt. In the theoretical introduction of this article, it was emphasized that lifelong learning enables entrepreneurs and individuals in general, to develop new skills and to expand knowledge in fields of interest for them. Through the research of several scientific papers, it came out that entrepreneurs should focus their learning efforts on topics like economic trends, technology, consumer behavior, industry and marketing trends. If entrepreneurs manage to expand their knowledge on these topics, they are better equipped to face challenges encountered by their businesses and to find the right solutions in this regard.

A second aspect emphasized during the theoretical perspective referred to the importance of emotional intelligence as a facilitator of lifelong learning. As it is well known, entrepreneurs, especially those at the beginning of their path, have difficulties in balancing all the aspects of their businesses. Time is scarce for them, and learning might come in the last place. Therefore, entrepreneurs should identify solutions or they should adopt certain habits that will allow them to practice lifelong learning.

As a result of the interview and survey, it was observed that young entrepreneurs lack the necessary time to dedicate sufficient effort for lifelong learning. They focus mostly on networking and asking advice from mentors and business partners, but they pay less attention to learning materials, which could help them to obtain a better understanding of the business environment. However, this research leaves no doubt over the fact that these entrepreneurs are open to discover new improvements to their businesses.

This paper provides the reader with a series of lessons that target not only entrepreneurs but individuals in general. For example, as it is well known, time is an issue for the current generation. A lack of time prevents entrepreneurs from better preparing themselves for encountering difficulties with their businesses. As demonstrated by the research, entrepreneurs are opened to expand their knowledge on fields important for their businesses, but they hardly find the time to read or listen learning materials. Therefore, their focus is on networking and learning by doing. Consequently, young entrepreneurs forget to create a strategy for achieving the vision set for their ventures.

This study repeatedly emphasizes the importance of education in forming entrepreneurs able to face the obstacles of the business environment. It is not all about learning certain subjects, but also about teaching young people to assume initiative in organizing their time and priorities, in choosing the field they want to specialize in, and in selecting the appropriate learning materials and practices for them. To sum up, young people should be thought to create a strategy for their professional life and to follow this strategy in order to achieve their personal goals.

\section{References}

Aleandri, G. and Refrigeri, L. (2013). Lifelong learning, training and education in globalized 
economic systems: analysis and perspectives. Procedia - Social and Behavioral Sciences. 93, $1242-1248$.

Areekul, C., Ubol, A. and Kimpee, P. (2015). Model development for strengthening social capital for being a sustainable lifelong learning society. Procedia - Social and Behavioral Sciences. 191, 1613-1617.

Bratianu, C. (2007). Thinking patterns and knowledge dynamics. In D. Remenyi (Ed.). Proceedings of the $8^{\text {th }}$ European Conference on Knowledge Management (pp. 152156), Consorci escolar Industrial, Barcelona, Spain, 6-7 September 2007. Reading: Academic Conferences and Publishing International.

Bratianu, C. (2009). The frontier of linearity in the intellectual capital metaphor. In C. Stam (Ed.). Proceedings of the European Conference on Intellectual Capital (pp.97-103), Inholland University of Applied Sciences, Haarlem, The Netherlands, 28-29 April 2009. Reading: Academic Conferences and Publishing International.

Hanewald, R. (2012). Cultivating life-long learning skills in undergraduate students through the collaborative creation of digital knowledge maps. Procedia - Social and Behvioral Sciences. 69, $847-853$.

Hollowitz, J. and Wilson, C. (1993). Structured interviewing in volunteer selection. Journal of Applied Communication Research. 21, 41-52.

Jirgensons, M. (2015). Direct assessment initiatives within a lifelong learning context. Procedia Computer Science. 43, 141-146.

Kakouris, A. (2015). Entrepreneurship pedagogies in lifelong learning: emergence of criticality. Learning, Culture and Social Interaction. 6, 87-97.

Laal, M. (2013). Key necessities for lifelong learning. Procedia - Social and Behavioral Sciences. 83, 937-941.

Laal, M. (2013). Lifelong learning and technology. Procedia - Social and Behavioral Sciences. 83, 980-984.

Rosenthal, M. (2016). Qualitative research methods: why, when and how to conduct interviews and focus groups in pharmacy research. Currents in Pharmacy Teaching and Learning. 8, 509-516. 